\title{
Development of Musical Ideas in Compositions BY TORTOISE
}

\author{
Reiner Krämer
}

\section{Prologue}

For more than 25 years, the Chicago-based experimental rock band Tortoise has crossed over multiple popular music genres (ambient music, krautrock, dub, electronica, drums and bass, reggae, etc.) as well as different types of jazz music, and has made use of minimalist Western art music. ${ }^{1}$ The group is often labeled a pioneer of the "post-rock« genre. Allegedly, Simon Reynolds first used the term in his review of the album Hex by the English east London band Bark Psychosis (Reynolds 1994a) and shortly afterwards in his article "Shaking the Rock Narcotic (Reynolds 1994b: 28-32). In connection to Tortoise he used "post-rock" in his review article of their 1996 album Millions Now Living Will Never Die (Reynolds 1996). Reynolds describes music he labels as spost-rock « where bands use guitars »in [non-rock] ways « to manipulate »timbre and texture rather than riff[s]《 and »augment rock's basic guitar-bass-drums lineup with digital technology such as samplers and sequencers « (Reynolds 2017: 509). Most members of Tortoise act as multiinstrumentalists that play different combinations of instruments at different times. As Jeanette Leech (2017: 16) has stated, a typical Tortoise stage setup can feature vibraphones, marimbas, two drum sets, and a multitude of synthesizers. With regards to the instrumental setup Leech draws up parallels with progressive rock of the 1970s but points to one decisive difference within the genres: "for Tortoise, the range of instrumentation [is] about creating mood, not showboating (ibid.).

More importantly and of particular importance to Tortoise, since the band does not have a singer in its line-up, post-rock "parts with such notions as the singer as storyteller and the song as narrative, source of life-

1 Tortoise's band name speculatively aligns itself with La Monte Young's 1964 composition »The Tortoise, His Dreams and Journeys, « in which instruments improvise over an electronic drone (Nicholls 1996). 
wisdom, or site of social resonance (Reynolds 2017: 509). In regard to vocals in post-rock music Osborn (2010: 51) states that »post-rock subverts rock tradition by nearly always removing the vocals«. Querying Music Brainz-a community-maintained open source encyclopedia of music information (music brainz.org)-reveals that there are about 365 other bands labeled "post-rock « at the time of writing. The top 10 groups include Godspeed You! Black Emperor, Mogwai, Sigur Rós, 65daysofstatic, MONO, Tortoise, Do Make Say Think, Explosions in the Sky, Caspian, and God is an Astronaut.

Because Tortoise cannot rely on text to propel musical motion, the ensemble developed a unique communicative musical style. Studying Tortoise's corpus might enable us to gain a better understanding of post-rock instrumental genres, and can also give us insights into collective compositional processes and multi-timbral/textural musical narratives.

In the music of Tortoise, musical ideas are often broken down into smaller elements or fragments, using melodic, rhythmic, harmonic, textural, contrapuntal, timbral transformations, and long-ranging formal transformation, creating recognizable recurring music features. These features create musical narratives. How do the different types of episodic developments relate to one another? Are the fragments overt or hidden? In what way is episodic material self-similar and how does it serve the musical narrative?

This study will try to answer these questions by laying out the ground work for a two-dimensional corpus study in the future, consisting of (1) the corpus of all recorded pieces (the »written $\ll^{2}$ ), and (2) different performed versions of the same piece in live, remix, or radio performance contexts (the »spoken «), highlighting discrete musical narratives of particular importance. The study focuses on the latter part of the two-dimensional corpus, from which three different compositions (»Along the Banks of Rivers, « »Jetty, « and »Salt the Skies«) are analyzed and compared to different versions. By focusing on the second dimension (»the spoken «), I am able to distinguish whether a piece is based on improvisation-using form as guideposts-,its form is fluid, or whether it is through-composed. Hereafter, the study can serve as a launching point for a comparative study of instrumental music by other bands of the "post-rock « genre, in order to be able to tag bands with actual music metadata and establish relationships based on this newly found data.

2 In linguistics a multidimensional corpus study »has been used to address issues such as the relations among spoken and written genres in English « (Biber 1992: $331)$. 


\section{Tools Used and Building a Tortoise Corpus}

The following data has been collected by applying web scraping techniques with the Python programming language. All data processing has also been completed by way of Python and the Python data analysis library pandas (https: //pandas.pydata.org). Graphs were drawn using the Python matplotlib library (https: //matplotlib.org, access: June 1, 2018).

Tortoise's musical output or corpus is constantly growing because the band is still actively touring and producing music. The corpus can be quantified by querying several online resources, such as musicbrainz.org, the Internet Archive (archive.org), allmusic.com, and discogs.com. Additionally, the Thrill Jockey website, Tortoise's label (thrilljockey.com/artists/ tortoise), the bands' website (trts.com), and the Brainwashed website (brainwashed.com/tortoise/) provide additional discographic information to assemble a complete picture of the corpus.

MusicBrainz shows that Thrill Jockey has released eight full-length albums, two compilations, five remix collections, two EPs, and ten singles by Tortoise. Each of these releases can have multiple editions for different dates and countries that may include different tracks. Overall, there are ca. 170 different recorded titles in Tortoise's all-inclusive corpus. In addition, the Internet Archive holds 1055 live recordings of individual compositions spanning from 1994-2017. One can divide Tortoise's corpus up into an outlier corpus and a core-corpus. The outlier corpus includes all pieces that have not been performed live (including remixes), of which there are ca. 60 recordings. The core-corpus includes all live performances of titles available at the Internet Archive and ranks the number of performances of these titles. The three compositions chosen for the ensuing study (»Along the Banks of Rivers, « »Jetty, « and »Salt the Skies«) have been chosen from the corecorpus because a multidimensional study, as previously described, can only be completed with a core-corpus. Table 1 displays the core-corpus, and shows how many different live versions are available at the Internet Archive (titles are separated by semicolon). The table also shows from which album each track originates (albums separated by semicolon correspond to titles separated by semicolon). 


\begin{tabular}{|c|c|c|}
\hline Title & $\begin{array}{l}\text { Live Perfor- } \\
\text { mances }\end{array}$ & Album \\
\hline $\begin{array}{l}\text { "In Sarah, Mencken, Christ, and } \\
\text { Beethoven There Were Women and } \\
\text { Men« }\end{array}$ & 71 & TNT \\
\hline "I Set My Face to the Hillside & 67 & TNT \\
\hline$\gg$ Eros « & 65 & Standards \\
\hline »Monica« & 63 & Standards \\
\hline "Swung From the Gutters« & 60 & TNT \\
\hline "Seneca « & 59 & Standards \\
\hline »Dot/Eyes« & 58 & It's All Around You \\
\hline »Crest « & 55 & It's All Around You \\
\hline "Salt the Skies « & 49 & It's All Around You \\
\hline »Ten Day Interval« & 47 & TNT \\
\hline »High Class Slim Came Floatin' In « & 37 & Beacons of Ancestorship \\
\hline »Prepare Your Coffin« & 35 & Beacons of Ancestorship \\
\hline $\begin{array}{l}\text { "The Suspension Bridge at Iguazu } \\
\text { Falls« }\end{array}$ & 34 & TNT \\
\hline $\begin{array}{l}\text { »Benway } \text {; } \\
\text { »DJed « }\end{array}$ & 33 & $\begin{array}{l}\text { Standards; } \\
\text { Millions Now Living Will Never Die }\end{array}$ \\
\hline »Gigantes« & 31 & Beacons of Ancestorship \\
\hline $\begin{array}{l}\text { "Taut \& Tame«; } \\
\text { »Tin Cans \& Twine« }\end{array}$ & 30 & Millions Now Living Will Never Die \\
\hline »Charteroak Foundation« & 27 & Beacons of Ancestorship \\
\hline »Magnet Pulls Through« & 25 & Tortoise \\
\hline$\gg$ It's All Around You« & 24 & It's All Around You \\
\hline »Stretch (You Are All Right)《 & 23 & It's All Around You \\
\hline $\begin{array}{l}\text { »Five Too Many«; } \\
\text { »Minors« }\end{array}$ & 21 & $\begin{array}{l}\text { It's All Around You; } \\
\text { Beacons of Ancestorship }\end{array}$ \\
\hline »Yinxianghechengqi & 20 & Beacons of Ancestorship \\
\hline $\begin{array}{l}\text { »Eden } 2 \ll ; \\
\gg \text { Glass Museum }\end{array}$ & 17 & $\begin{array}{l}\text { Standards; } \\
\text { Millions Now Living Will Never Die }\end{array}$ \\
\hline $\begin{array}{l}\text { »Gamera«; } \\
\text { »The Equator« }\end{array}$ & 15 & $\begin{array}{l}\text { Millions Now Living Will Never Die } \\
\text { (Japan) }\end{array}$ \\
\hline $\begin{array}{l}\text { »Along the Banks of Rivers«; } \\
\text { »NT « }\end{array}$ & 14 & $\begin{array}{l}\text { Millions Now Living Will Never } \\
\text { Die; TNT }\end{array}$ \\
\hline $\begin{array}{l}\text { »Cornpone Brunch«; } \\
\text { »The Catastrophist« }\end{array}$ & 11 & $\begin{array}{l}\text { Tortoise; } \\
\text { The Catastrophist }\end{array}$ \\
\hline $\begin{array}{l}\text { »Gesceap«; } \\
\text { »The Lithium Stiffs« }\end{array}$ & 10 & $\begin{array}{l}\text { The Catastrophist; } \\
\text { It's All Around You }\end{array}$ \\
\hline »Night Air« & 9 & Tortoise \\
\hline $\begin{array}{l}\text { »On the Chin«; »Shake Hands With } \\
\text { Danger«; »Yonder Blue« }\end{array}$ & 9 & $\begin{array}{l}\text { It's All Around You; The } \\
\text { Catastrophist; The Catastrophist }\end{array}$ \\
\hline $\begin{array}{l}\text { »At Odds With Logic «; } » \text { Jetty «; } \\
\text { »Everglade «; »Hot Coffee «; }\end{array}$ & 8 & $\begin{array}{l}\text { The Catastrophist; TNT; } \\
\text { The Catastrophist; TNT }\end{array}$ \\
\hline $\begin{array}{l}\text { »Aldeia de Ogum «; } \\
\text { »Reservoir« }\end{array}$ & 7 & $\begin{array}{l}\text { Peel Session; A Digest Compen- } \\
\text { dium of the Tortoise's World }\end{array}$ \\
\hline $\begin{array}{l}\text { »Firefly«; »Six Pack«; } \\
\text { "Spiderwebbed« }\end{array}$ & 6 & $\begin{array}{l}\text { Standards; Standards; } \\
\text { Tortoise }\end{array}$ \\
\hline
\end{tabular}




\begin{tabular}{|c|c|c|}
\hline Title & $\begin{array}{l}\text { Live Perfor- } \\
\text { mances }\end{array}$ & Album \\
\hline $\begin{array}{l}\text { »Speakeasy«; »Tesseract«; } \\
\text { »The Clearing Fills«; »Wait« }\end{array}$ & 5 & $\begin{array}{l}\text { Standards; The Catastrophist; The } \\
\text { Catastrophist; A Lazarus Taxon }\end{array}$ \\
\hline 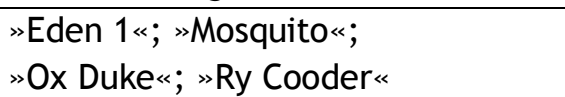 & 4 & $\begin{array}{l}\text { Standards; Tortoise (Japan); } \\
\text { The Catastrophist; Tortoise }\end{array}$ \\
\hline $\begin{array}{l}\text { »A Survey«; } \\
\text { »Reservoir Sheets«; »Sheets«; } \\
\text { »Vaus« }\end{array}$ & 3 & $\begin{array}{l}\text { Millions Now Living Will Never } \\
\text { Die; Lonesome Sound; Lonesome } \\
\text { Sound; Vaus }\end{array}$ \\
\hline $\begin{array}{l}\text { »Daniel«; »Gooseneck«; } \gg \text { Love Is } \\
\text { Love«; »On Noble«; »The Lawn of } \\
\text { the Limp« }\end{array}$ & 2 & $\begin{array}{l}\text { The Brave and the Bold; } \\
\text { Mosquito; The Brave and the } \\
\text { Bold; Tortoise; In the Fishtank }\end{array}$ \\
\hline $\begin{array}{l}\text { »Almost Always Is Nearly Enough «; } \\
\text { »Deltitnu«; »Monument Six One } \\
\text { Thousand «; »Othello«; »The Fall of } \\
\text { Seven Diamonds Plus One«; »The } \\
\text { Match Incident« }\end{array}$ & 1 & $\begin{array}{l}\text { TNT; It's All Around You (Japan); } \\
\text { Beacons of Ancestorship; A } \\
\text { Lazarus Taxon; Beacons of Ances- } \\
\text { torship; Rhtyhms, Resolutions \& } \\
\text { Clusters }\end{array}$ \\
\hline
\end{tabular}

Table 1: Tortoise Core-Corpus.

\section{»Along the Banks of Rivers«}

The track "Along the Banks of Rivers" appears on Tortoise's 1996 album Millions Now Living Will Never Die. According to Andrew Earles (2014: 334), the album »changed part of the underground rock landscape for the rest of the '90s and earned the band, for better or worse, the label sgodfathers of American post rock «. The piece closes the album, and to Michael Shields (2016) it is a »a fitting swan song to this classic work of art; an atmospheric, affectionate kiss good night where softly swirling guitar and bass riffs lull you into a fantastical dreamscape «. Sonically, the composition evokes scenes from a »lambent Ennio Morricone (Salamon 1996: 113) scored ItaloWestern movie or perhaps surf music, due to the electric guitar timbre, a sound that Reynolds (1995: 29) describes as »lugubrious spy movie TripHop, « and that "calls to mind Angelo Badalamenti's film scores from the late 1980" (Novara/Henry 2009: 828). Tortoise uses the Italo-Western surf guitar and bass combination the first time on Millions Now Living Will Never Die and revisits the sound on the albums TNT (especially on the tracks »TNT, «» Set My Face To The Hillside «) and Standards (»Six Pack, « "Blackjack«) etc. A query to the Internet Archive hosts 13 live recordings of the song ranging from 1996 to 2017 (the site also reveals that there are a total of 116 live recordings of Tortoise's concerts altogether). The 21-year life span is a testament of the song's importance within Tortoise's core-corpus. 
The album version of »Along the Banks of Rivers « (on which the following analysis is based on) consists of a clearly defined formal structure. The composition starts with a regular pulse emerging from transitional material held over from the previous track »Dear Grandma and Grandpa.« The bassstyle pulse is centered around pitch class $\gg$ 《 and occurs at regular intervals around 60 beats per minute (bpm), setting up a 4/4 meter. The introductory section lasts 12 seconds and ends with an anacrusis that consists of a three eighth note grouping (G3, D4, Eb4 respectively-where middle $C$ is $C 4$ ) beginning on beat 3.5. The goal of the anacrusis is $C 4$ on beat 1 , which concludes the initial motif $a(00: 12-00: 20)$. The second iteration of motif $a, a^{\prime}$, begins on beat 3.5 with $\mathrm{G} 3$ and reuses the previous motif, , but changes its rhythmic material on beat 4 of the anacrusis to a triplet figure consisting of D4, Eb4 and C4, and adds D4 as its goal note on beat 1 . The third iteration $\left(a^{\prime \prime}\right)$ of the initial motif, also beginning on beat 3.5 with $\mathrm{G} 3$, adapts the triplet figure from the second motif iteration $a^{\prime}$, including its pitch content in order, but its goal now changes from D4 (beat 1) to B3 (beat 1.5). The developmental process through the two additional iterations of motif $a$ is that of accretion.

The musical idea (MI1) ends with a three-note motif, beginning on beat 3.5 with D4, continuing to beat 4.5 with Eb4, and concluding on beat 1 with $\mathrm{C} 4$, or motif $b$. The module is called $\mathrm{A}(00: 12-00: 48)$, and its main goal is to establish a key center around pitch class C by moving from C4 up to D4, down to B3, and returning to $\mathrm{C} 4$. The key of $A$ is firmly situated in $\mathrm{C}$ minor. A encompasses nine measures. The example indicates the ninth measure as being a rest in the guitar. However, the drum set creates a measure-long fill in its place. Example 1 shows MI 1 in the A section. It should be noted that a musical idea does not always pair up with an entire section of a piece, as the analysis of the other pieces will reveal.

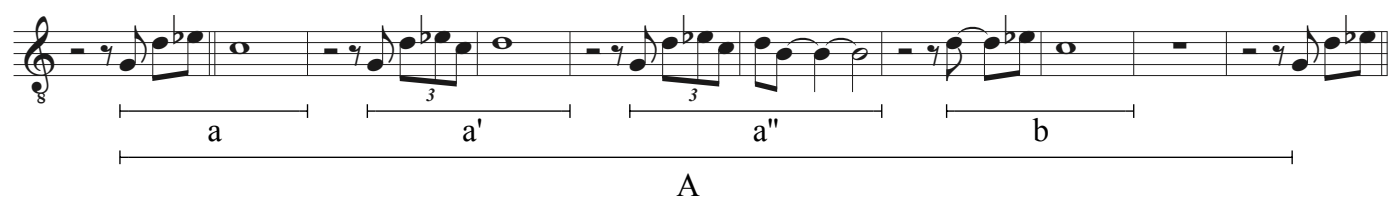

Example 1: Musical Idea 1 (MI1) in the A Section of "Along the Banks of Rivers.«

The second musical idea (MI2) occurs in the $A^{\prime}$ section (00:48-01:20) and is almost identical to MI 1 in the A section, except that now the idea spans eight measures, rather than nine (example 2). Tortoise thereby plays with the listener's expectations. When hearing $A$ the listener wants to hear only 
eight measures, but gets nine, while in $A^{\prime}$ the listener's expectation seems to be fulfilled.

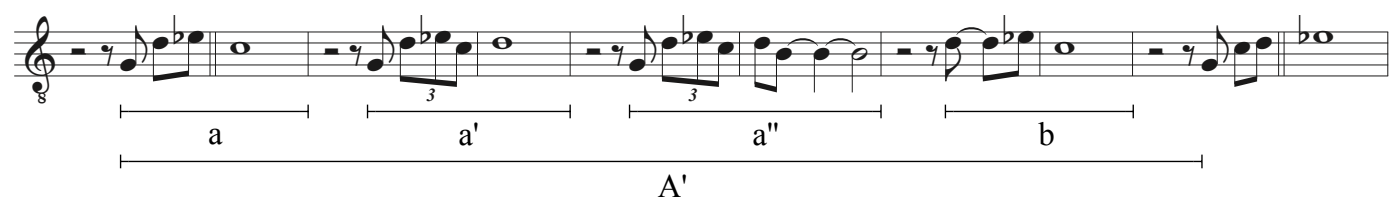

Example 2: MI2 in the A' Section of »Along the Banks of Rivers.«

Example 3 shows a third musical idea (MI3) occurring in the B section (01:20-01:55) that is again nine measures long. As was the case with the previous $A$ and $A^{\prime}$ sections, Tortoise uses accretion to develop an initial motif $a$ in its consecutive iterations $\left(a^{\prime}\right.$ and $\left.a^{\prime \prime}\right)$. The module returns to pitch center $C$ using motif $b$. The goals of each motif are Eb4, F4, G4, F4, Eb4, and $\mathrm{C} 4$ respectively, indicating a move to the mediant of $\mathrm{C}$ minor, and returning to the tonic.

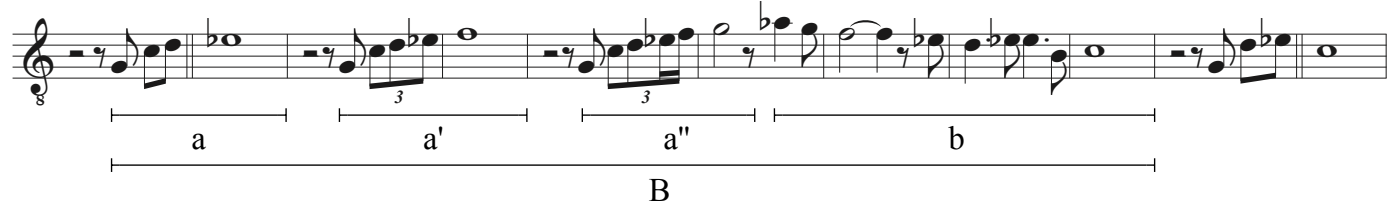

Example 3: MI3 in the B Section of »Along the Banks of Rivers.«

After the B section, the piece returns to another $A^{\prime}$ section $(01: 55-02: 27)$, which is eight measures in length. At this point, the listener may expect the conclusion of the AABA form, common to rock music, with the caveat that the form spans 34 measures rather than 32. However, Tortoise then returns to the $B$ section (02:27-03:03), where the $b$ ' motif has also been expanded by one measure as previously, in order to incorporate a transitional drum fill that introduces the next section. The procedure seems to be necessary, because the $C$ section (03:03-05:00) changes the meter to 6/8. Metric shifts and rhythmic variety are a core feature of Tortoise's music, perhaps because the band has two drummers (although all members of the band play the drums at various times).

The $C$ section changes the key and serves as a sort of solo section in which the guitar performs a series of 21 slides, as if to imitate an object that rides the waves of the river flow. Those 21 guitar slides are performed in an unpredictable ascending or descending pattern. The slides span $8+8+$ $8+8+8$ measures +2 additional measures as a reaction of a communicative nod, whereas the penultimate measure of the group represents the apex of the section by way of a continuous rising motion as represented by the 21 
slide patterns. The last measure of the group serves as a drum transition back to the 4/4 time signature of the ensuing $A^{\prime}$ section (05:00-05:32). The last four measures are the ending section of the track (05:32-05:51). Table 2 summarizes the form of the studio version of »Along the Banks of Rivers. «

\begin{tabular}{|c|c|c|c|}
\hline Start & Module (Section) & Measures & Motifs \\
\hline $00: 00$ & Intro & & Transition \\
\hline $00: 12$ & \multirow[t]{4}{*}{ A } & \multirow[t]{4}{*}{$(1)+8+1$} & $\mathrm{a}$ \\
\hline $00: 20$ & & & $a^{\prime}$ \\
\hline $00: 28$ & & & $\mathrm{a}^{\prime \prime}$ \\
\hline $00: 36$ & & & $\mathrm{~b}$ \\
\hline $00: 48$ & \multirow[t]{4}{*}{$A^{\prime}$} & \multirow[t]{4}{*}{8} & $\mathrm{a}$ \\
\hline $00: 56$ & & & $a^{\prime}$ \\
\hline 01:04 & & & a" \\
\hline $01: 12$ & & & $b^{\prime}$ \\
\hline 01:20 & \multirow[t]{4}{*}{$B$} & \multirow[t]{4}{*}{$8+1$} & $\mathrm{a}$ \\
\hline 01:28 & & & $a^{\prime}$ \\
\hline 01:36 & & & a" \\
\hline 01:44 & & & $\mathrm{b}$ \\
\hline 01:55 & \multirow[t]{4}{*}{$A^{\prime}$} & \multirow[t]{4}{*}{8} & $a$ \\
\hline 02:04 & & & $a^{\prime}$ \\
\hline $02: 11$ & & & a" \\
\hline 02:19 & & & $b^{\prime}$ \\
\hline $02: 27$ & \multirow[t]{4}{*}{$\mathrm{B}^{\prime}$} & \multirow[t]{4}{*}{$8+1$} & $\mathrm{a}$ \\
\hline $02: 35$ & & & $a^{\prime}$ \\
\hline $02: 43$ & & & $\mathrm{a}^{\prime \prime}$ \\
\hline $02: 52$ & & & $\mathrm{~b}^{\prime}$ \\
\hline 03:03 & C & $8+8+8+8+8+(2)$ & Solos \\
\hline 05:00 & \multirow[t]{4}{*}{$A^{\prime}$} & \multirow[t]{4}{*}{8} & $\mathrm{a}$ \\
\hline 05:08 & & & $a^{\prime}$ \\
\hline $05: 16$ & & & a" \\
\hline 05:23 & & & $b^{\prime}$ \\
\hline $05: 32$ & End & 4 & Ending \\
\hline
\end{tabular}

Table 2: Form of »Along the Banks of Rivers« (album version).

The recorded form of »Along the Banks of Rivers, « however, only represents the exception to how Tortoise performs the track in a live setting (figure 1). The $y$-axis displays the number of performances, which are 14 altogether (one studio, 13 live), i.e. when looking at the transition or introduction section, only six of the performances included this section. Out of the 13 available live performances, only one performance from 1996 strictly follows the form recorded on Millions Now Living Will Never Die. The other 13 perfor- 
mances use the following formal structure: Introduction (pulses emerging from various crowd or stage noises that set the mood and tempo of the piece in the first 30 seconds, including a rimshot on beat one of the measure containing the anacrusis to A), A (the section ends with drum fills of various lengths after the eighth measure to bewilder the listeners expectations), $A^{\prime}, B$, then they omit $A^{\prime}$ and $B^{\prime}$ and continue directly with $C$ (solos of varying lengths, not only consisting of guitar slides), $A^{\prime}$, and an ending. From the performances a clearer case for an altered AABA form can be made, whereby $A A B A$ (or $A A^{\prime} B|C| A^{\prime}$ ) has been interjected by a solo section (C).

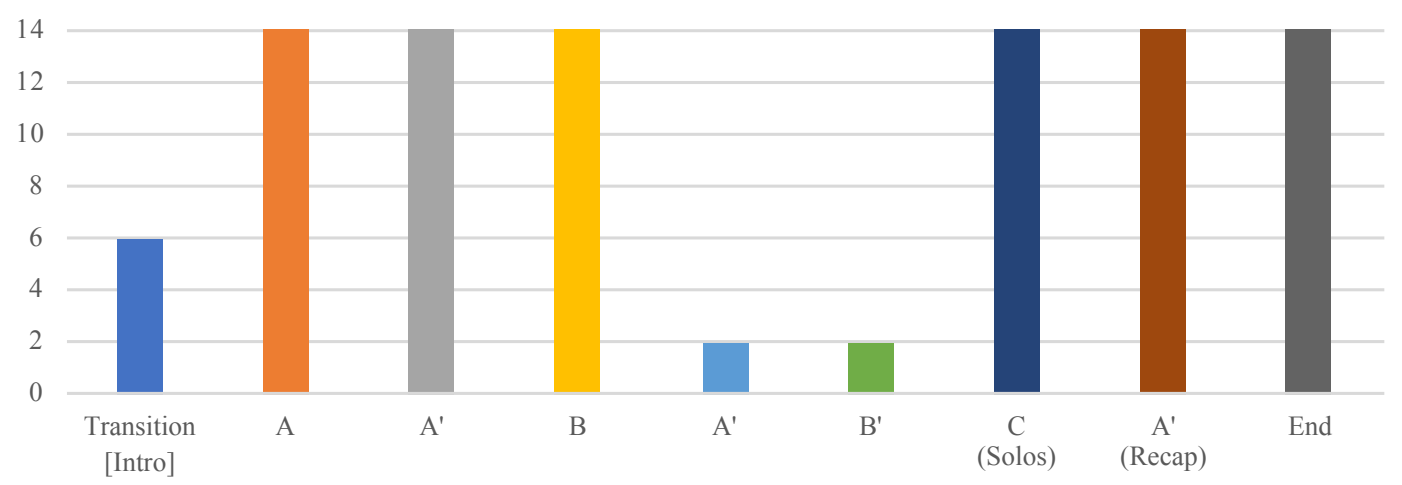

Figure 1: Individual Section Occurrences in »Along the Banks of Rivers. «

How Tortoise changed the form of the piece over time is presented in figure 2Figure 2. The $y$-axis expresses the number of sections and which sections were played during each performance of the piece, while the $x$-axis specifies when each performance was played and whether it was recorded live or in the studio. Changing forms during different performances points to the modularity of the different sections and the improvisatory character of the piece.

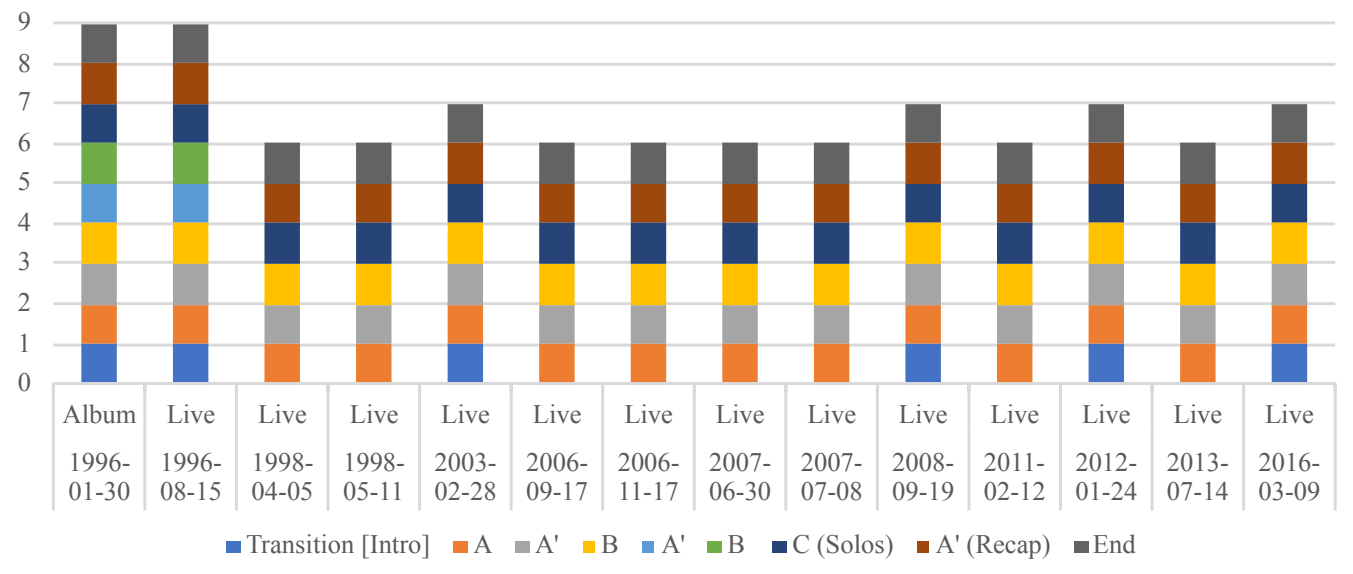

Figure 2: »Along the Banks of Rivers, « Section Changes Over Time. 
»Along the Banks of Rivers« highlights one of the techniques that Tortoise uses frequently throughout their core-corpus, namely the development of a motif through accretion, as for example the interpolated accretion in »Ten Day Interval« on the TNT album.

\section{»Jetty《}

La Jetée is a 28-minute black and white 1962 science fiction short film built from still photos by the French film maker Chris Marker. The time travel story involves a prisoner protagonist, »the man, « being sent to multiple different time periods by a group of scientists. Eventually »the man« recognizes himself in one of the time periods and tries to prevent his own ultimate demise. "La Jetée « is also the title of the third track off of the Chicagobased band Isotope 217's 1997 album The Unstable Molecule. The group consists of members from Tortoise and the Chicago Underground (Kampmann 2001). »Jetty« is a re-interpretation of »La Jetée « and appears as the eleventh track on Tortoise's 1998 album TNT one year later. »Jetty« reflects the narrative of the film by using a chaconne-styled re-iterative ground bass and chord progression. It is not uncommon for music of the jazz, blues, and rock ' $n$ ' roll genres to make use of this type of lamento bass, as can be heard for example in Robert Johnson's »Walkin' Blues, « the Eagles' »Hotel California, " or Led Zeppelin's »Dazed and Confused« (Ross 2004). Example 4 shows Tortoise's »Jetty« bass line. Although descending bass lines occur in other pop and rock music types, the term chaconne has been deliberately chosen because the composition is an instrumental piece.
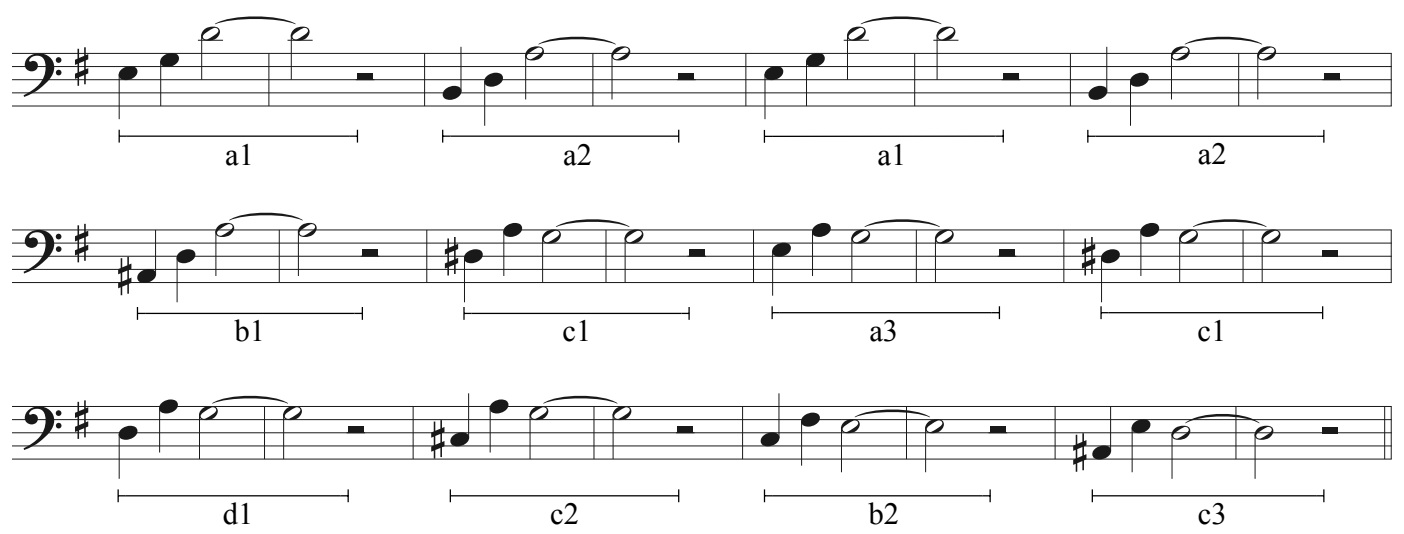

Example 4: Bass Line in »Jetty.«

The bass line in »Jetty « (first heard at 2:12, see ex. 4) consists of 12 motifs and is 24 measures in length. All of the motifs utilize the same rhythmic 
motif (s[hort]-s[hort]-l[ong]; notice that the tied-half note is arbitrary, the decay of the bass note may be longer or shorter at times). The 12 motifs consist of four discrete, separate motifs (presented as a, b, c, and d). If a motif is repeated exactly, it shares the same number; if it is transformed, a different number has been added to the lowercase letter. Therefore, a2, consisting of the pitch-class collection $\{E, 2,9\}$ or $\{B, D, A\}-[9, E, 2]$ or $[A$, $B, D]$ in normal form-is transposed by a perfect fourth down (a.k.a. 7 halfsteps up, or $\mathrm{T}_{7}$ ) from a1. All »a« motifs belong to set-class (025). The b1 and b2 (b2 in normal form reads as $[0,4,5]$ or $[C, E, F]$, thus $T_{4}$ from b1, which reads as $[9, T, 2]$ or $[A, B b, D])$ motifs belong to set-class (015), whereas $c 1$, $c 2$ ( $T_{4}$ from $c 1$ ), and $c 3$ ( $T_{7}$ from $c 2$ ) belong to set-class (026). Motif $d$ belongs to set-class (027). The overall trajectory of the bass line is descending, especially starting from m. 13 onward, providing more evidence for the chaconne-like form. The bass plays a chromatically descending line on the downbeat on every other consecutive measure, with the exception for $\mathrm{mm}$. 21 and 23 where the bass descends by step, or E, Eb, D, C\#, C, and Bb.

\begin{tabular}{|l|l|l|}
\hline Time Start & Chaconne (Measures) & Events \\
\hline $00: 00$ & Intro $(24+16)$ & Electronic Drums, Synth Bass Voices \\
\hline $01: 00$ & i1 $(24)$ & Bass, Synth Brass, Voices \\
\hline $01: 36$ & i2 (24) & Bass \\
\hline $02: 12$ & i3 (24) & descending Bass \\
\hline $02: 48$ & i4 (24) & Melody Module 1 \\
\hline $03: 24$ & i5 (24) & Melody Module2 \\
\hline $04: 00$ & i6 (24) & Melody Module3 \\
\hline $04: 36$ & i7 (24) & Melody Module4 \\
\hline $05: 12$ & i8 (24) & Solo 1 \\
\hline $05: 48$ & i9 (24) & Solo 2 \\
\hline $06: 24$ & i10 (24) & Solo 3 \\
\hline $07: 00$ & i11 (24) & Solo4 \\
\hline $07: 36$ & i12 (24) & Melody Module5 \\
\hline $08: 13$ & End (2) & a1 \\
\hline
\end{tabular}

Table 3: Formal Structure of the Studio Version of »Jetty.«

The resulting structure (which will now be referred to as $\gg j<-i t e r a t i o n)$ built with the bass figure occurs 12 times in »Jetty« (see table 3 ) and is 24 measures long. A bipartite prologue $(24+16)$ at the beginning of the track and an epilogue with a monopartite ending ( 2 measures at 08:13) flank these iterations. The composition moves swiftly at about $160 \mathrm{bpm}$ in 4/4 time, and begins with a two-part prologue of an electronically altered 
drum-groove, presumably played by the two drummers in the group, along with a two-chord tonic-(minor)dominant oscillation. The second part adds a synth generated brass part to the two-chord oscillation drum groove $(00: 36)$. The two-chord oscillation eventually becomes part of i1 (revisit the first eight measures of the bass line in example 4).

During i1 decorative chords-chords that do not serve a specific harmonic function, that may be different with each iteration-and a synthesized child-like voice are added to the continued drum groove and the synthesized and/or special-effects brass part. In i2 the brass and child voices drop out, and a proto-bass is established that is not related to the actual ground bass part. However, in $i 3$ the listener hears the bass figure the first time. During i4 the complementary musical idea is added to the texture of the bass line, chords, and drums (example 5 displays the chaconne's melodic material). Tortoise uses accretion again, but this time to create the complete texture of the chaconne.
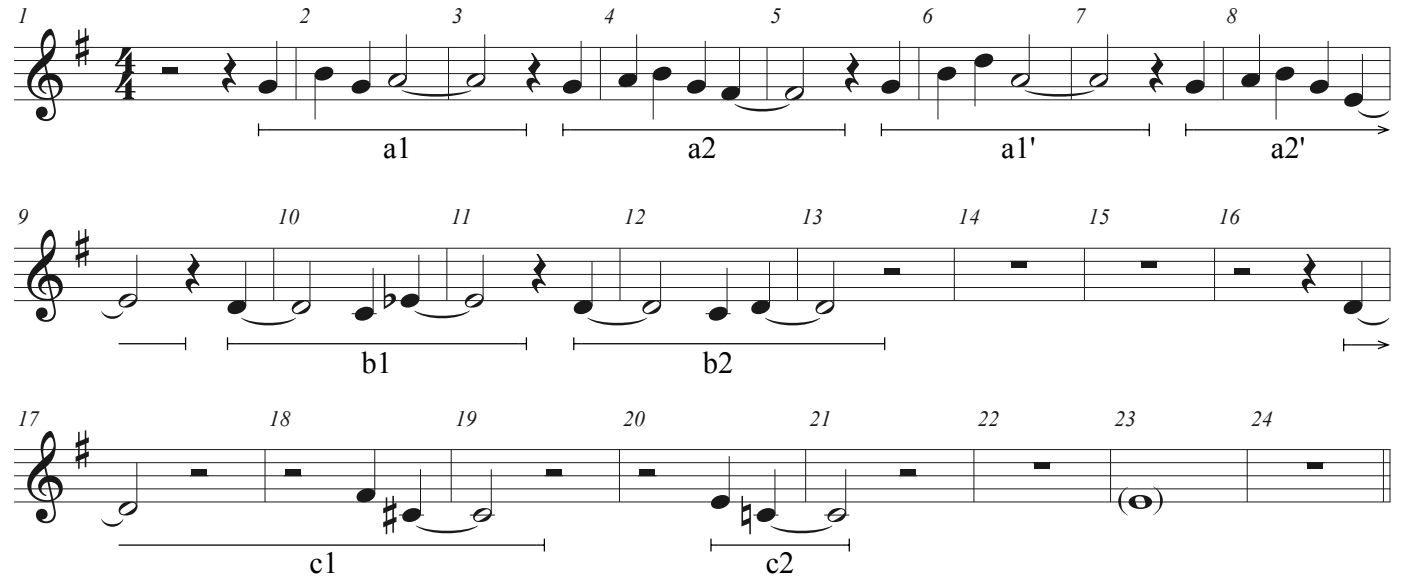

Example 5: Melody Part of the Chaconne in »Jetty.«

The chaconne's melody part consists of eight different interrelated motifs. The $a$-group confirms what the bass line has set up to be the key of e minor. Motif a1 represents an encircling motion to A4 by way of G4 and B4 and sets up an s-s-s-l rhythmic motif. The following motif $a 2$ uses an interpolation to add A4 at its onset in between G4 and B4, but rather than ending on A4, it reaches its goal on F\#4, all while using an s-s-s-s-l rhythmic motif. Motif a1' is almost identical to $a 1$, except that it uses a leap up to D5, which then reaches its goal of $\mathrm{A} 4$. However, a1' maintains its rhythmic relationship to a1. In motif $a 2^{\prime}$ the goal changes from F\#4 to E4, while the rest of the pitch material remains identical to $a 2$. The rhythmic material of $a 2^{\prime}$ is congruent to that of $a 2$. By changing the goal of $a 2$ ', a chromatic descent from E4, 
Eb4, to D4 on the pick-ups to measures 9, 11, and 13 respectively, foreshadows the succeeding chromatically descending bass line beginning in measure 13, which is the main purpose of motifs $b 1$ and $b 2$, both of which have identical l-s-l rhythmic motifs (example 7). As the bass begins its descent in $\mathrm{m} .13$, the melodic line becomes rather sparse and only two motifs (c1 and c2) that are more fragmentary develop.

Motif c1 rhythmically consists of an l-s-l gesture, where the first note D4 recalls the end of the descent in $\mathrm{m} .13$, and the last note, as was the case with the other descent, continues the descent as a pick-up to $\mathrm{m}$. 19 with C\#4. The subsequent motif $c 2$ is a depletion of $c 1$, only re-iterating the $s-l$ rhythmic gesture, but continuing the descending line with a $\mathrm{C} 4$ anacrusis to m. 21. Further, the descending line in the melody module, or musical idea, consists of the same pitch-class material as the line presented in the bass part. Example 5 highlights the descents in the melodic module and the bassline. The E4 in m. 23 prepares the listener for the chaconne to begin anew, and it is parenthesized, because sometimes it occurs singularly, whereas other times it occurs with decorative chordal notes.
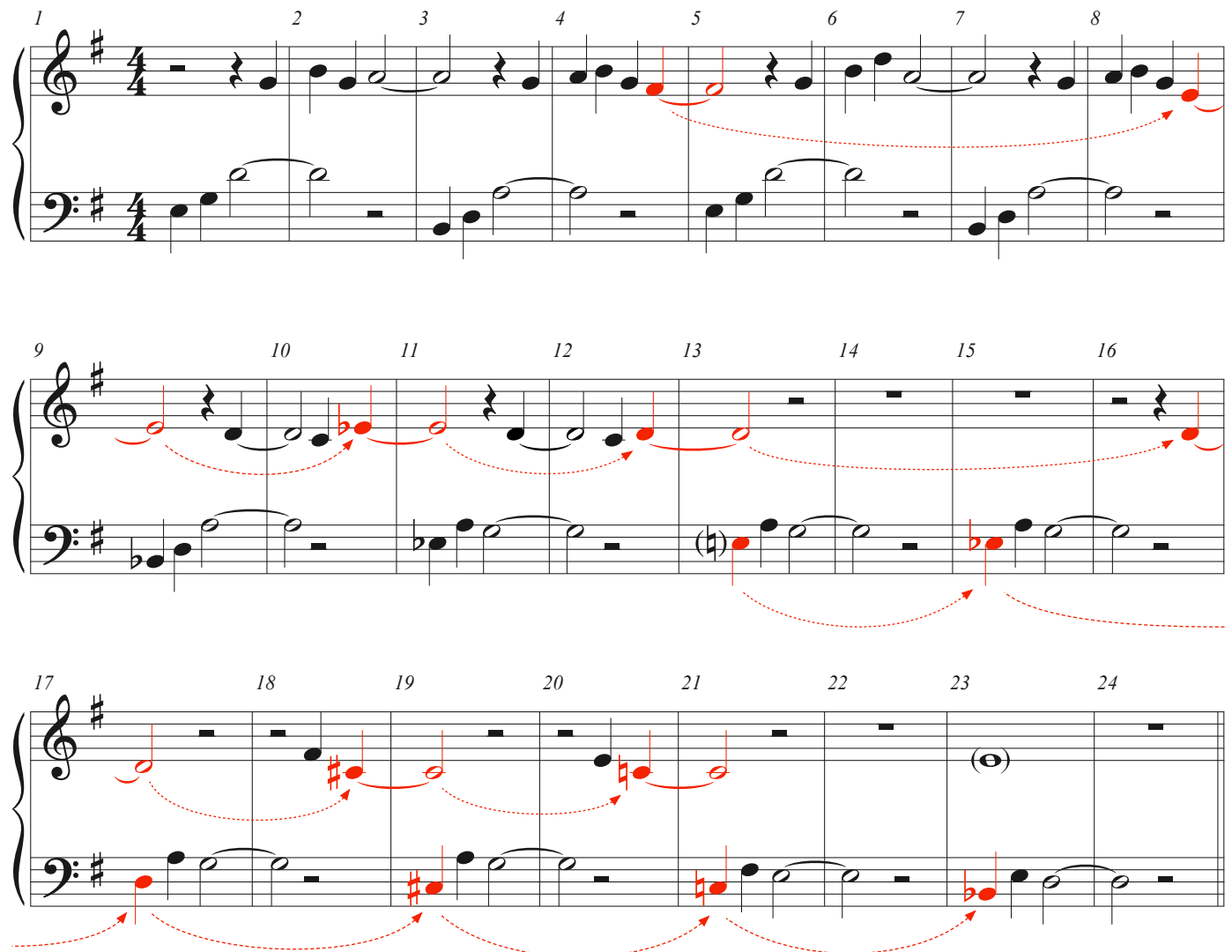

Example 6: Descents in the Melody and Bass

Returning to the iterations of the chaconne, a synthesizer and guitar combination make up the timbre of the melodic module in i4 (timbre 1), while in 
i5 Tortoise adds a vibraphone to the module, thickening the timbral combination (timbre 2). In i6 Tortoise thins-out the timbral texture at first by only using a vibraphone and, about halfway through the iteration, by adding the guitar back in (timbre 3). Tortoise applies i5's timbral combination to i7, or reuses timbre 2 . These past four iterations (i4-i7) present the musical idea of the chaconne in order to create different timbral shadings. Guitarist Jeff Parker ${ }^{3}$ performs a guitar solo during i8 and i9 (two iterations), while a drum solo is the focus of $i 10$. In i11, a non-virtuosic rhythmic keyboard solo is performed, and the drum solo continues, highlighting more possible chordal decorations of the iterations, while $\mathrm{i} 12$ is a recapitulation or reprise of $i 5$ and $i 7$ because timbre 2 is reused. The epilogue is a monopartite ending which uses the first motif $a 1$ of the melody without any chordal decorations, drums, or the bass line, representing a break of »the man«'s cycle, and thereby creating a non-conclusive ending.

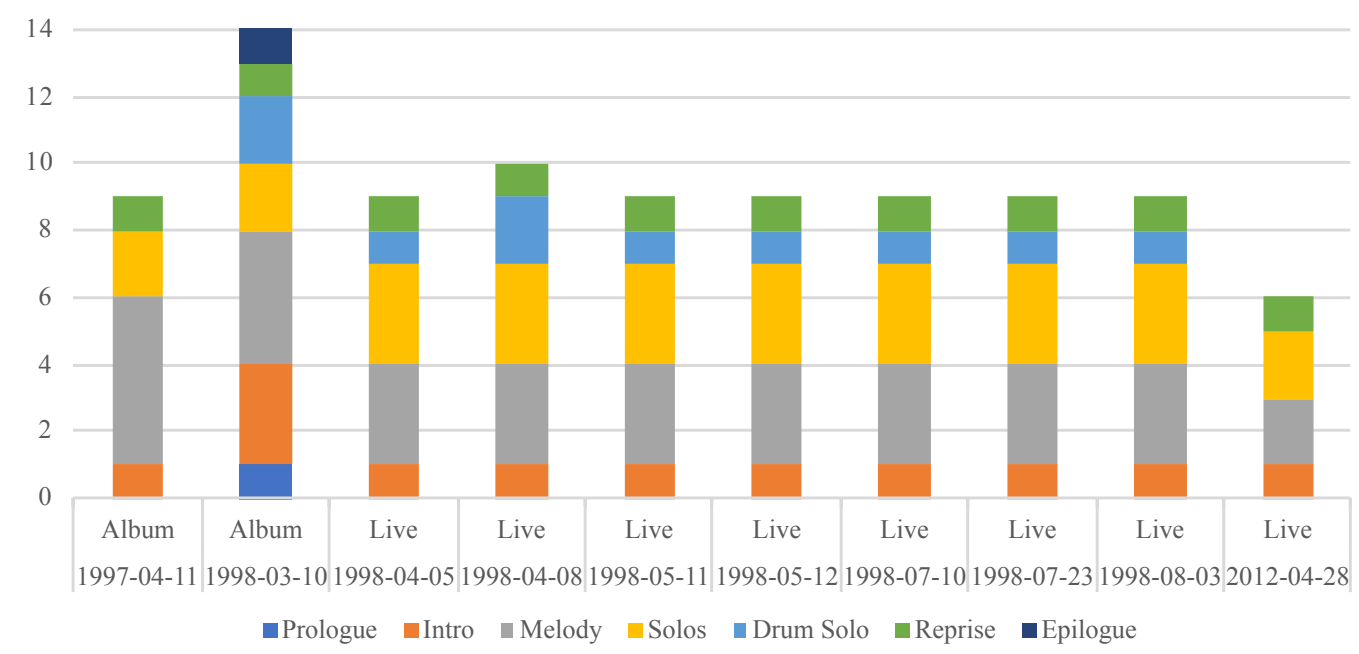

Figure 3: »Jetty« Forms.

While observing all 10 available recordings of "Jetty (figure 3 ), i.e. the two studio recordings-Isotope 217's The Unstable Molecule (1997-04-11), Tortoise's TNT respectively (1998-03-10)-and the eight available live recordings from the Internet Archive, it becomes clear that »Jetty's « formal structure on the TNT studio recording is an exception. For the majority of performances, the chaconne resembles the studio recording of Isotope 217's "La Jetée « on The Unstable Molecule. On the live recordings, the chaconne is most often played nine times, whereas the first iteration is an introduction. The reprise consistently presents the chaconne and uses a ritardando in lieu of using the epilogue ending featuring the $a 1$ motif from the melody

3 More on Jeff Parker and his influences can be found in Holt (2014: 105-150). 
part. The musical idea occurs three times after the introduction, including the timbral variations laid out in the studio recording by Tortoise, whereas solos occur for the duration of three iterations. Before the reprise occurs, another chaconne iteration features a drum solo.

Additionally, listening to the live recordings also highlights the fluidity by which chords are added by the keyboardist and the guitarist. In most iterations, the chords are varied and only function as timbral decoration for the drum grooves, the musical idea, and the descending bass line. Furthermore, the bass line and the musical idea are somewhat more fluid, meaning that the studio recording merely outlines their pitch class content, while the musicians in practice add and subtract pitch classes, and also vary their rhythms according to the ensembles' and audiences' energies during performances. Figure 3 also shows that there are only live recordings available within a year from the album TNT's release, except for one in 2012. The 2012 recording stays somewhat true to the versions from the late 1990s, but is abbreviated quite a bit; in fact, it only features six iterations instead of nine as was the case with the other live recordings. Naturally, just because no other live recordings are available does not necessarily mean that Tortoise seldom performs the piece.
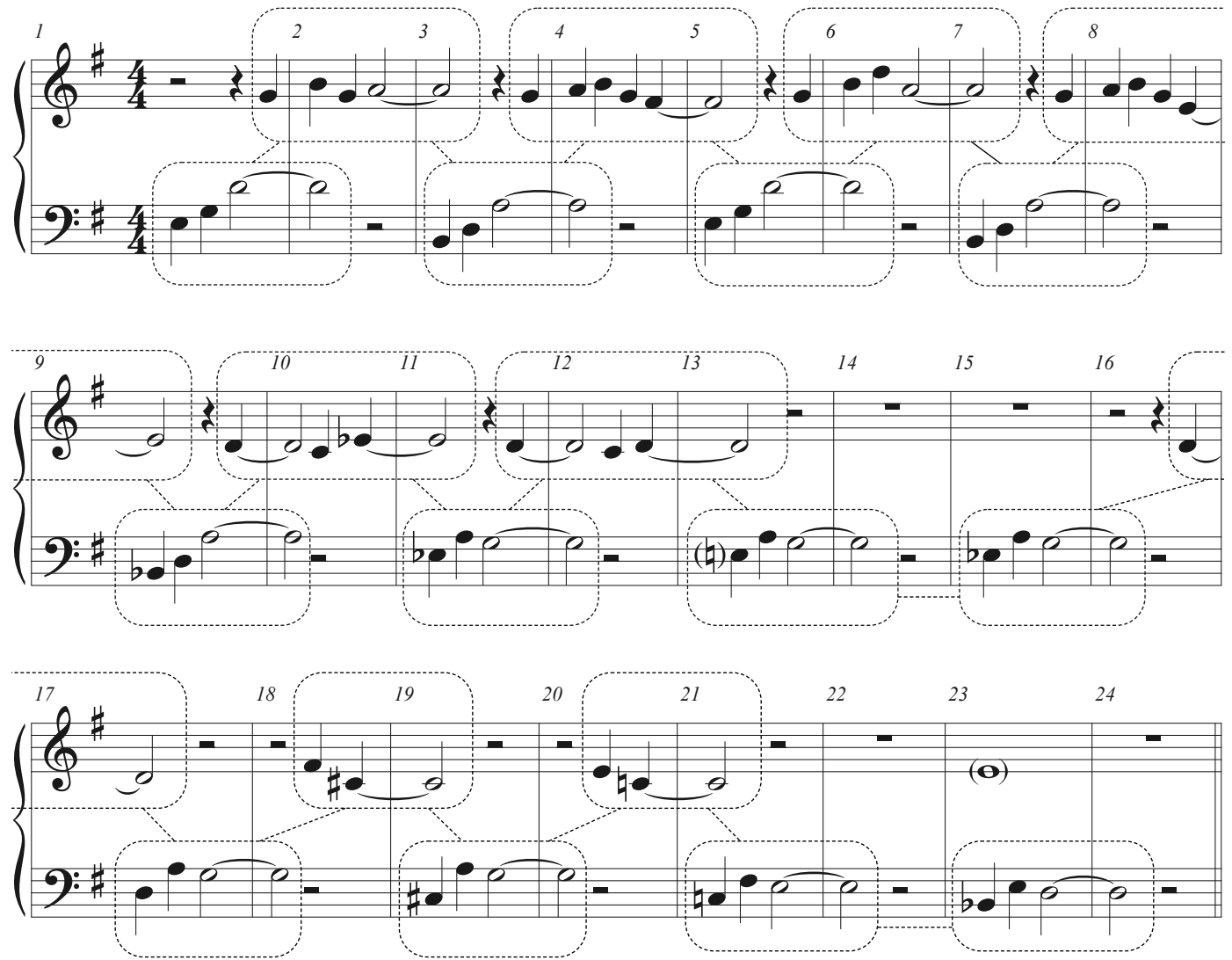

Example 7: Interconnectivity of Chaconne Melody and Bass. 
Although both the melody and the bass part are important individual features of the chaconne musical idea, they are also intricately interconnected (example 7) and, through their symbiotic relationship, make the chaconne a distinguishable gestalt. The bass and melody parts create a kind of call response figure, which can work independently, but also together.

Tortoise frequently uses the development of this type of musical idea in their core-corpus, especially when developing different timbral combinations. In »Jetty, « Tortoise's narrative depends on the musical idea of the chaconne. Its repetition portrays the scientist sending »the man« multiple times through the time machine to different eras, but in the end the chaconne's »bass line is a fate from which we cannot escape« (Ross 2004).

\section{»Salt the Skies«}

» Salt The Skies captures the quintet gloriously galvanised in ebbing from plaintive jazz to free-flowing post-punk rawness « (Pannett 2009). The piece closes Tortoise's 2004 release It's All Around You. Tortoise's 2006 box-set release $A$ Lazarus Taxon includes a video of a live performance in a living room. Although MusicBrainz lists ten additional, mostly live recordings, aside from various releases of the studio recording, a query of the Internet Archive reveals that a total of 49 live recordings of "Salt the Skies« are available. The initial discussion begins with the studio version of »Salt the Skies. «

The composition begins with a short musical idea (MI1) in the A section, reminiscent of a change ringing algorithm, or »bell-like « clockwork (»AAJ Staff « 2004), initially performed by a guitar and vibraphone in a Klangfarbenmelodie manner, foreshadowing ensuing timbral switches (examples 8). The tempo is ca. $80 \mathrm{bpm}$.

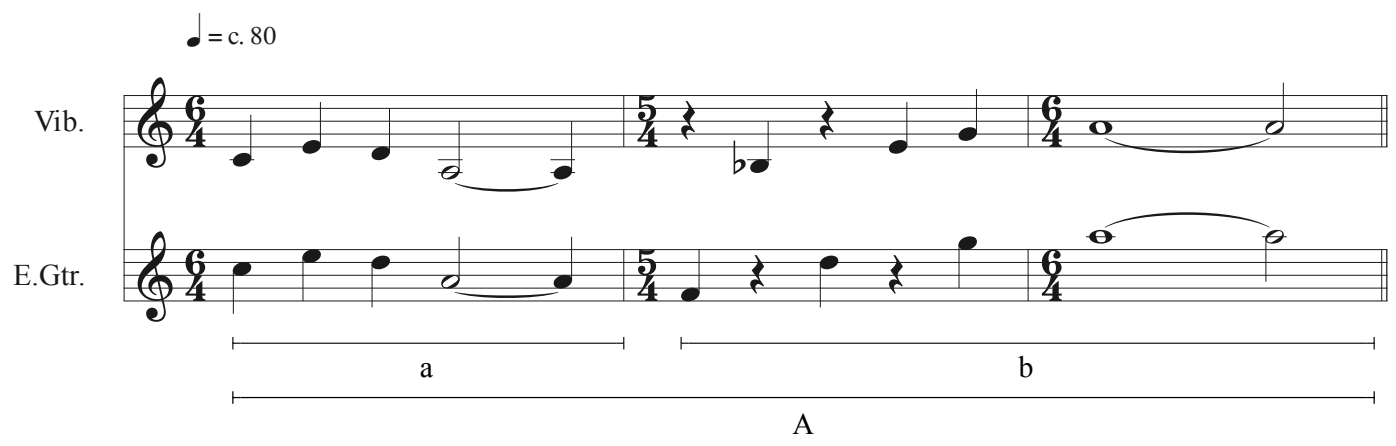

Example 8: »Salt the Skies« initial Musical Idea (MI1). 
The musical idea $(0: 00-00: 13)$ uses time signature changes, $6 / 4$ to $5 / 4$ returning to $6 / 4$, which could have been strictly written out, or perhaps resulted from the free interplay of the musicians. The first part of the musical idea (a), the question, consists of a downward motion from scale degree 3 (mediant) to scale degree 1 , while the answer (b) is fractured between the vibraphone and the electric guitar and moves upward from scale degree 6 (sub-mediant) to scale degree 1 , resulting in an octave displaced tonic. The effect is that of perhaps an imperfect authentic cadence, where the listener is left with longing for continuance. A Morse code sound artifact sample can be heard during the first exposure in section $A$. The musical idea is reiterated a second time (with drums, bass, and a keyboard) by an electric piano (timbral transformation), and this time with meter changes from 6/4 to $5 / 4$ to $4 / 4$, further pointing to coincidental meter changes $(00: 13-00: 25)$. On the third iteration of the musical idea (00:25-00:36), the previous meter changes are maintained, the timbre is changed back to guitar and vibraphone, while maintaining the previously added drums, bass and keyboard parts. The three iterations of A thereby create an introduction to the piece. Also, because the musical idea has been transformed twice in its reiteration, Tortoise has created a gestalt memory of the musical idea for us.

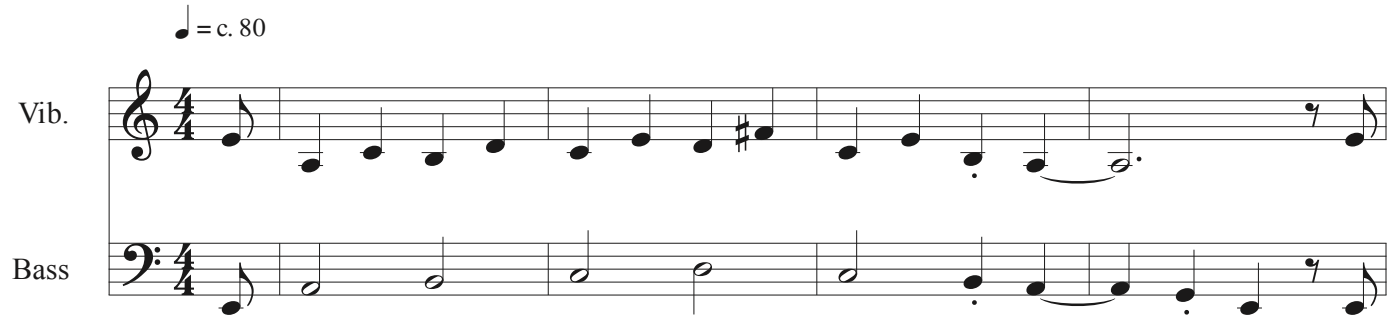

Example 9: B Section Ostinato 1.

The next section is 15 measures long $(00: 36-01: 18)$ and provides the $B$ section, after a four measure introduction of a vibraphone-bass-electric-pianodrums ostinato figure, ostinato 1 (example 9, here abbreviated to vibraphone and bass). Ostinato 1 establishes A Dorian as a key (00:36-00:47) and the tempo is held over from the previous introduction section. An electric guitar introduces the new musical idea (MI2) in the B section at 00:47 which is four measures long (example 10). MI2, as has been true for the majority of musical ideas thus far, is bipartite and can be subdivided into a question (a) and answer (b) area. The $a$ area moves from tonic to dominant, while the $b$ section moves from dominant to tonic. Ostinato 1 and MI2 repeat three times during this section. 
E.Gtr.

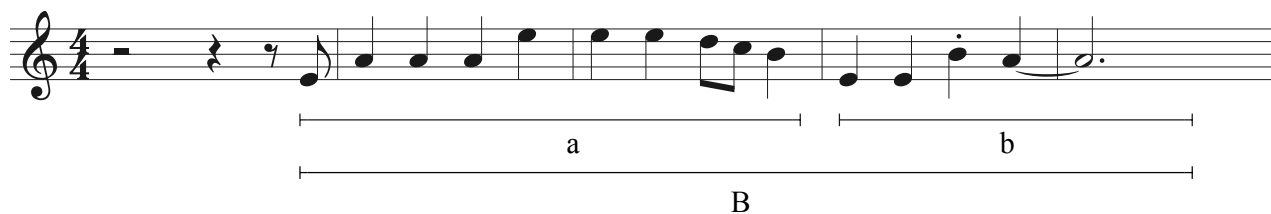

Example 10: Musical Idea (MI2), B Section.

After the third iteration of ostinato 1 and the second iteration of MI2 in the B section, a discontinuity occurs in the bass part (example 11) that leads to a new musical idea in an additional guitar part. The function of this discontinuity is to provide a transitional figure between this section and the next section (at the double bar line). The fourth iteration is not complete and the time signature changes to $3 / 4$. This change is another step in the transition that leads to the 6/8 time signature of the following section. Tortoise divides the 3/4 measure to one consisting of three groupings of two eighth notes, which then changes in the next measure to two groupings of three eighth notes, an effective rhythmic modulation. The bass in the $6 / 8$ measure, along with another guitar, plays ostinato 2 used in the $\mathrm{C}$ section.

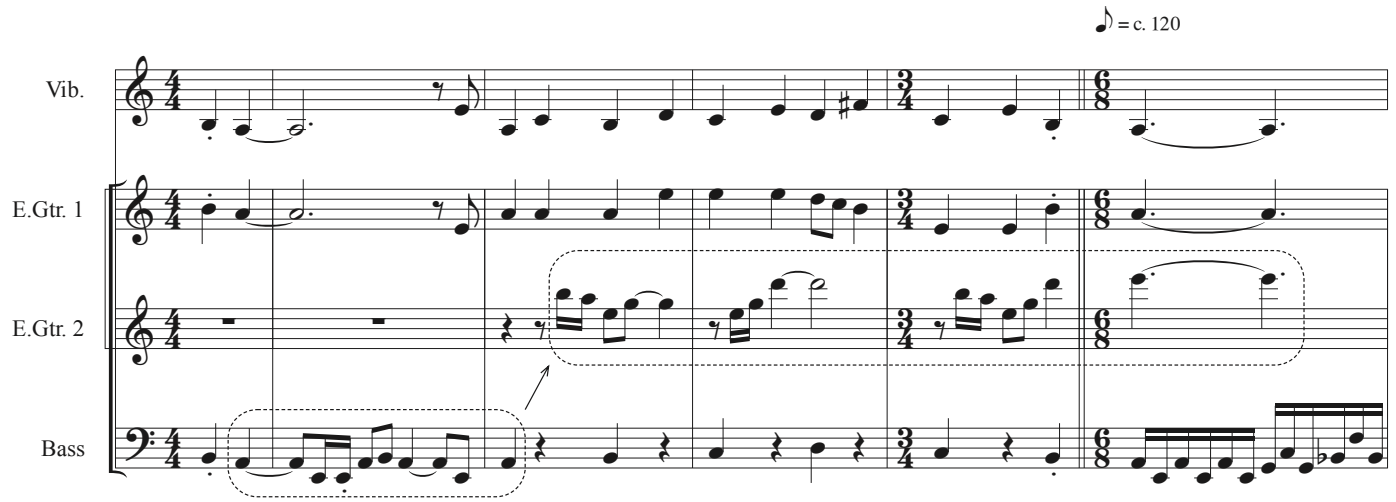

Example 11: Section B Transition.

The guitar-bass ostinato (consisting of an A-E oscillation implying the tonic of A Dorian or minor on the first beat, and outlining a minor seven $\mathrm{G}$ subtonic chord on the second beat in which $\mathrm{C} 3$ is used to get to $\mathrm{Bb} 2)$ of the $\mathrm{C}$ section accompanied by the drums is repeated eight times (01:18-01:41) before the entrance of the next musical idea (MI3). The repetition creates tension, grounds the listener within the new time signature, and builds up a sense of anticipation within the listener. The new melodic musical idea enters at 01:41 and features the timbral combination of electric-guitar-electricpiano-electric-bass. More striking is the juxtaposition of meters of the ostinato 2 pattern against the melodic musical ide: its 4:3 relationship. And al- 
though the musical idea is in 4 , it consists of a tripartite structure (example 12 displays a bass-vibraphone reduction).
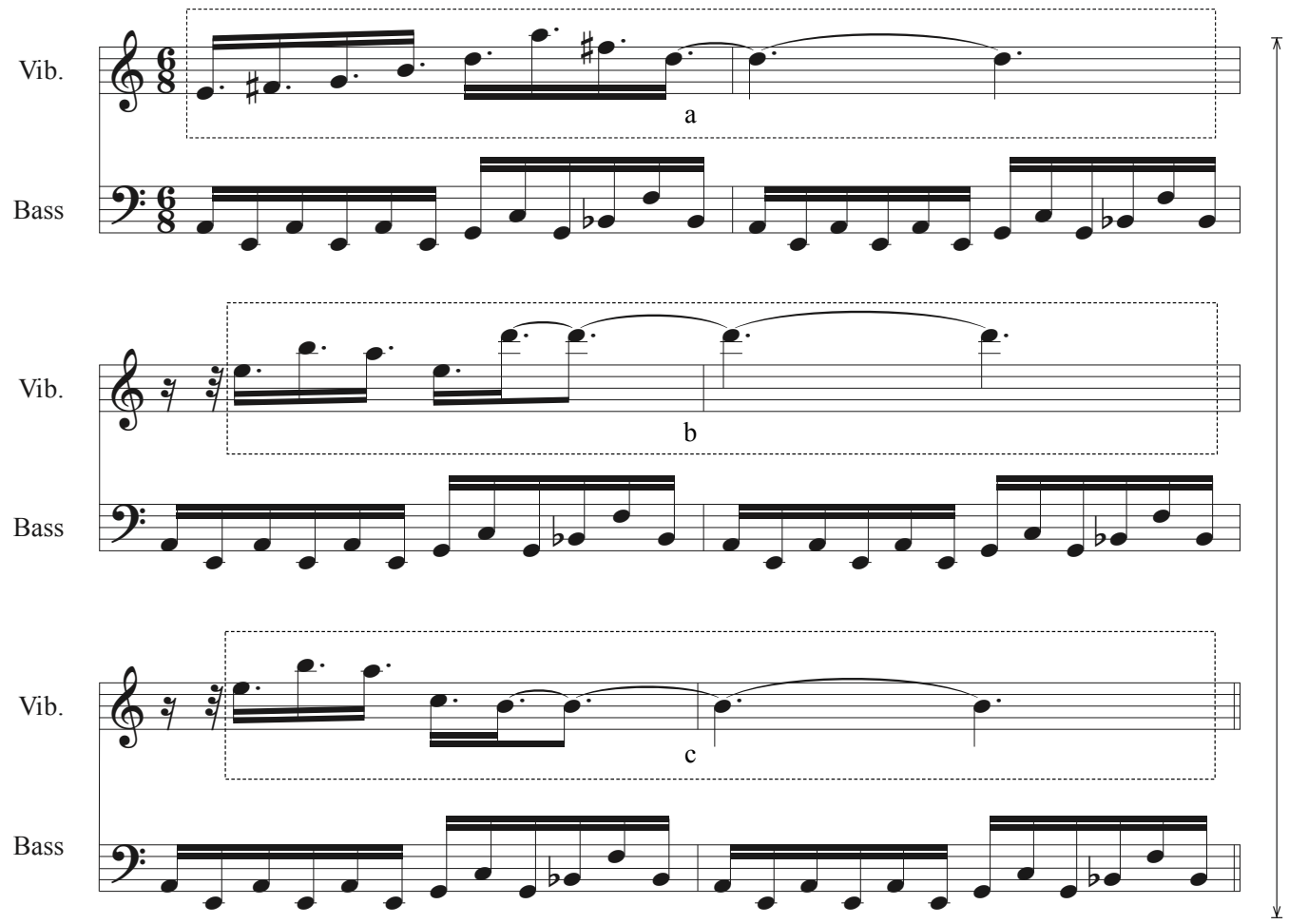

Example 12: Musical Idea (MI3) in Section C.

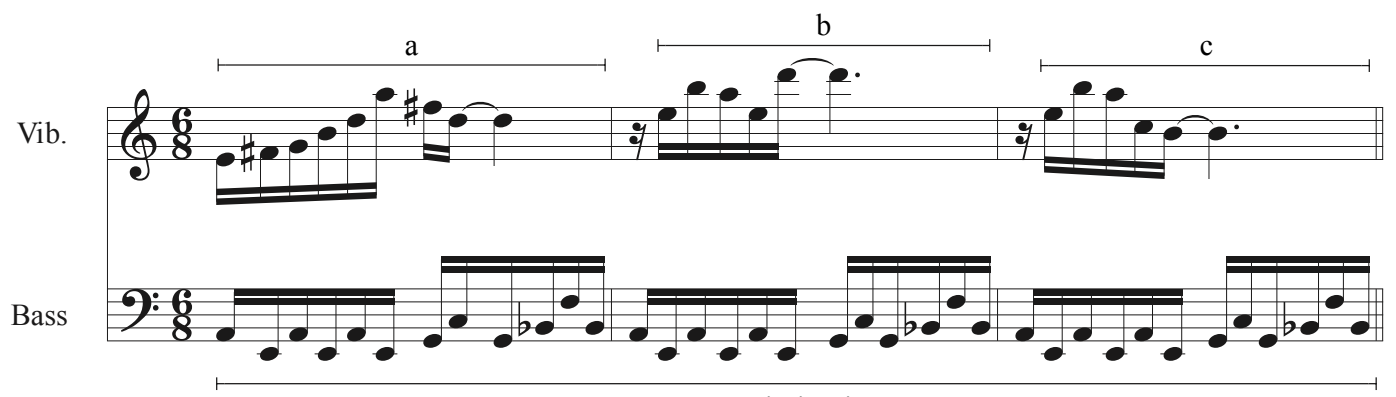

C2: Diminution

Example 13: Diminution of MI3 in Section C and Ostinato 2.

Section $C$ is in the minor dominant of A Dorian. The $a$ motif of MI3 ascends from E4 to D5, outlining an e minor $7^{\text {th }}$ with an added $9^{\text {th }}$ and $11^{\text {th }}$, while the $b$ motif ascends from E5 to D6. Although the pitch class collection of motif $b$ is different from the pitch class collection of motif $a$, the overall motion represents an octave displacement, which was observed in the introductory A section with motifs $a$ and $b$. Now, however, a $c$ motif is added, closing the musical idea with an overall descending motion from E5 to B4. MI3 repeats once more before the next iteration of the same idea is presented in diminution (02:15-02:27), one of the most common compositional transforma- 
tions of musical ideas, heightening the overall tension of the section (example 13). The diminution removes the $4: 3$ relationship of the musical idea and synchronizes the musical idea to the meter of the ostinato 2 pattern in $6 / 8$.

The diminution ushers in the next section $A^{\prime}$. In the $A^{\prime}$ section $102: 26-$ 03:55) the guitar-bass ostinato changes to a different pattern. Although the rhythmic motif of ostinato 3 has changed, the harmonic content remains the same, namely on beat 1 a pattern outlining (and this time clarifying) an a minor chord (tonic), and on beat 2 outlining a g minor $7^{\text {th }}$ chord (subtonic). As was the case in the previous $C$ section ostinato 3 occurs eight times before the entrance of the next musical idea (02:26-02:48). In addition, the drum set begins a drum solo that will continue throughout the remaining $A^{\prime}$ section and dovetail into the next section (02:26-04:03).

The following musical idea is motif a from MI 1 in the introductory A section (example 14). The motif is repeated by itself four times over the ostinato pattern (02:48-03:11) along with the drum solo, building tension while the listener, recalling the motif being part of the introduction, is longing for motif $b$ to complete MI1. Motif $a$ was non-metered in the introduction, or loosely used 6/4 meter in the transcription here, and Tortoise could have used the motif and placed it verbatim into $6 / 8$. Instead, the group places the motif into a 4:3 relationship, as was the case with the motivic material in the $C$ section, and thereby successfully rhythmically re-contextualizes its meaning.

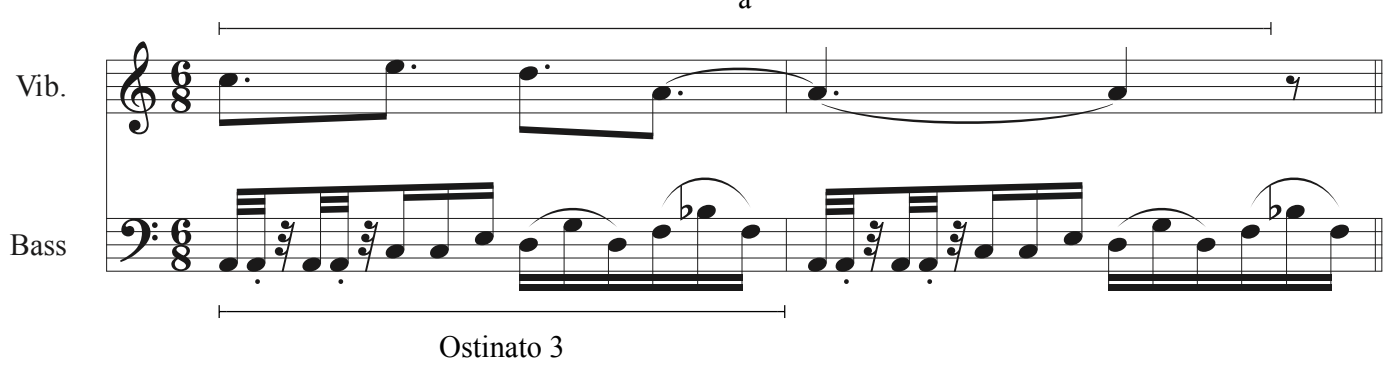

Example 14: A' Section Ostinato 3, Motif a from MI1.

Additionally, on the second repeat of motif $a$, the guitarist begins a distortion-based textural guitar solo that dovetails from the $A^{\prime}$ section into the next section (03:11-04:03), like the drum solo. When motif $a$ is played the fifth time, it is at last answered by motif $b$ to produce the complete musical idea $A$, all while the ostinato pattern, drum solo, and guitar solo continue (see table 4). This treatment of MI1 is a development from how the idea was presented in the introduction of the piece. Example 15 illustrates how MI1 is repeated a total of four times, and on the fourth time in the last 
measure of the $b$ motif, ostinato 3 changes back to the ostinato 2 of the previous $C$ section (03:11-03:55), and indeed another iteration of the $C$ section begins (03:55-04:26).

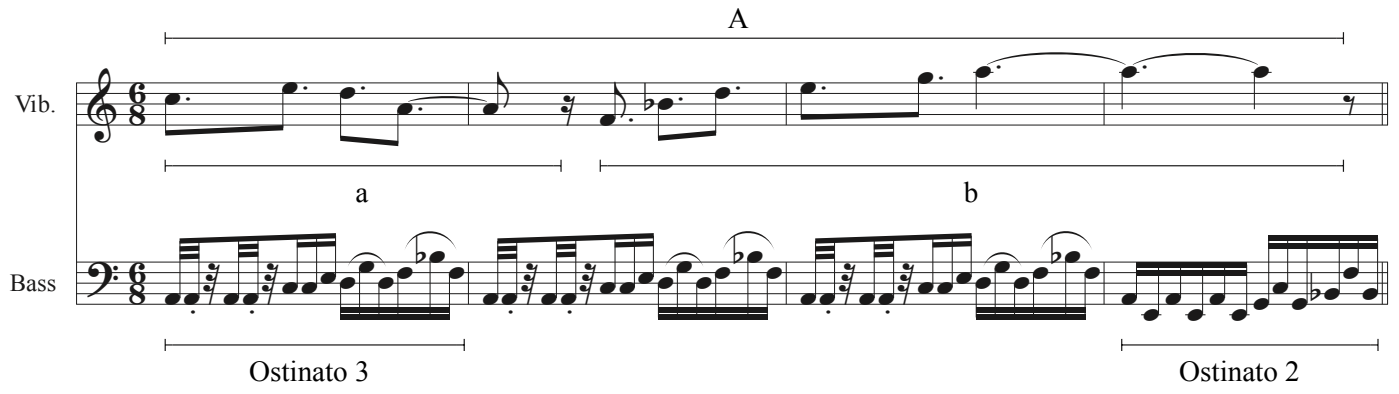

Example 15: A' Section Re-iteration of Ml1.

As was previously stated, the guitar and the drum solos continue for four measures into the $C^{\prime}$ section. When the solos end the MI3 is repeated twice (04:03-04:26), conveying a calming effect. At the end of the second MI3 iteration the ending section begins (04:26-04:46), re-stating the non-metered musical idea $A$ once more to further reduce the energy, and the piece ends with the return to pitch class $A$ at the end of motif $b$. The repetition of the non-metered musical idea $A$ thereby creates a frame narrative. Table 4 summarizes the form of "Salt the Skies. «

Since there are 50 different live recordings available (one from a live video of the 2006 A Lazarus Taxon box-set release, and the others on Internet Archive) a closer analysis of the form and performance practice is also possible. Figure 4 shows that all performances of the composition before its studio recording in 2017, spanning 14 years, were identical in regard to form. Even sub-formal sections as the ones previously described were maintained in detail. The figure shows that the piece is through-composed, although a solo-section has still been reserved for textural improvisation. The composition falls within one of four through-composed archetypes common in post-rock, namely type IV, the multi-part polythematic type (Osborn 2011). In fact, even the time spans of the different performances are within a 20 -second range. 


\begin{tabular}{|c|c|c|c|c|c|c|}
\hline $\begin{array}{l}\text { Start } \\
\text { Times }\end{array}$ & Sections & Musical Ideas & Measures & Motifs & Descriptions & Meter \\
\hline $00: 00$ & \multirow[t]{6}{*}{ A } & \multirow[t]{2}{*}{ MI1 } & 1 & $a$ & \multirow[t]{2}{*}{ Intro } & \\
\hline $00: 04$ & & & 2 & $b$ & & \\
\hline $00: 13$ & & \multirow[t]{2}{*}{ MI1 } & 1 & $\mathrm{a}$ & \multirow[t]{4}{*}{ Body } & \\
\hline $00: 17$ & & & 2 & $b$ & & \\
\hline $00: 25$ & & \multirow[t]{2}{*}{ Ml1 } & 1 & $a$ & & \\
\hline $00: 29$ & & & 2 & b & & \\
\hline $00: 36$ & \multirow[t]{7}{*}{ B } & & \multicolumn{2}{|l|}{4} & \begin{tabular}{|l|} 
Intro, \\
Ostinato 1
\end{tabular} & $\begin{array}{l}\text { Simple } \\
\text { Quadruple }\end{array}$ \\
\hline $00: 47$ & & \multirow[t]{2}{*}{ MI2 } & 2 & $\mathrm{a}$ & \multirow[t]{6}{*}{ Body } & \\
\hline $00: 53$ & & & 2 & $b$ & & \\
\hline $00: 59$ & & \multirow[t]{2}{*}{ MI2 } & 2 & $a$ & & \\
\hline 01:04 & & & 2 & $\mathrm{~b}$ & & \\
\hline $01: 10$ & & \multirow[t]{2}{*}{ MI2 } & 2 & $\mathrm{a}$ & & \\
\hline $01: 15$ & & & 2 & $b^{\prime}$ & & \begin{tabular}{|l} 
Simple \\
Triple
\end{tabular} \\
\hline $01: 18$ & \multirow[t]{10}{*}{ C } & & \multicolumn{2}{|l|}{8} & \begin{tabular}{|l|} 
Intro, \\
Ostinato 2 \\
\end{tabular} & $\begin{array}{l}\text { Compound } \\
\text { Duple }\end{array}$ \\
\hline $01: 41$ & & \multirow[t]{3}{*}{ MI3 } & 2 & $a$ & \multirow[t]{9}{*}{ Body } & \\
\hline 01:47 & & & 2 & $\mathrm{~b}$ & & \\
\hline $01: 53$ & & & 2 & C & & \\
\hline $01: 58$ & & \multirow[t]{3}{*}{ MI3 } & 2 & $a$ & & \\
\hline $02: 04$ & & & 2 & $b$ & & \\
\hline $02: 10$ & & & 2 & C & & \\
\hline $02: 15$ & & \multirow[t]{3}{*}{ MI3 } & 1 & $a^{\prime}$ & & \\
\hline $02: 18$ & & & 1 & $b^{\prime}$ & & \\
\hline $02: 21$ & & & 2 & $c^{\prime}$ & & \\
\hline $02: 27$ & \multirow[t]{13}{*}{$A^{\prime}$} & & 8 & & \begin{tabular}{|l|} 
Intro, \\
Ostinato 3
\end{tabular} & $\begin{array}{l}\text { Compound } \\
\text { Duple }\end{array}$ \\
\hline $02: 48$ & & \multirow[t]{6}{*}{ Ml1 } & 2 & $a^{\prime}$ & \multirow[t]{12}{*}{ Body } & \\
\hline $02: 54$ & & & 2 & $a^{\prime}$ & & \\
\hline $02: 59$ & & & 2 & $a^{\prime}$ & & \\
\hline 03:05 & & & 2 & $a^{\prime}$ & & \\
\hline $03: 10$ & & & 2 & $a^{\prime}$ & & \\
\hline $03: 14$ & & & 2 & $b^{\prime}$ & & \\
\hline $03: 21$ & & \multirow[t]{2}{*}{ MI1 } & 2 & $a^{\prime}$ & & \\
\hline $03: 25$ & & & 2 & $\mathrm{~b}^{\prime}$ & & \\
\hline $03: 33$ & & \multirow[t]{2}{*}{ MI1 } & 2 & $a^{\prime}$ & & \\
\hline 03:36 & & & 2 & $b^{\prime}$ & & \\
\hline $03: 44$ & & MI1 & 2 & $a^{\prime}$ & & \\
\hline $03: 47$ & & & 2 & b" & & \\
\hline $03: 58$ & $C^{\prime}$ & & 4 & & \begin{tabular}{|l|} 
Intro, \\
Ostinato 2 \\
\end{tabular} & $\begin{array}{l}\text { Compound } \\
\text { Duple }\end{array}$ \\
\hline 04:03 & & MI3 & 1 & $a^{\prime}$ & Body & \\
\hline 04:06 & & & 1 & $\mathrm{~b}^{\prime}$ & & \\
\hline 04:09 & & & 2 & $c^{\prime}$ & & \\
\hline $04: 14$ & & MI3 & 1 & $a^{\prime}$ & & \\
\hline $04: 17$ & & & 1 & $\mathrm{~b}^{\prime}$ & & \\
\hline $04: 20$ & & & 2 & $c^{\prime}$ & & \\
\hline $04: 26$ & $\mathrm{~A}^{\prime \prime}$ & MI1 & 1 & $a$ & & \\
\hline $04: 30$ & & & 3 & $b$ & & \\
\hline
\end{tabular}

Table 4: »Salt the Skies« Form. 


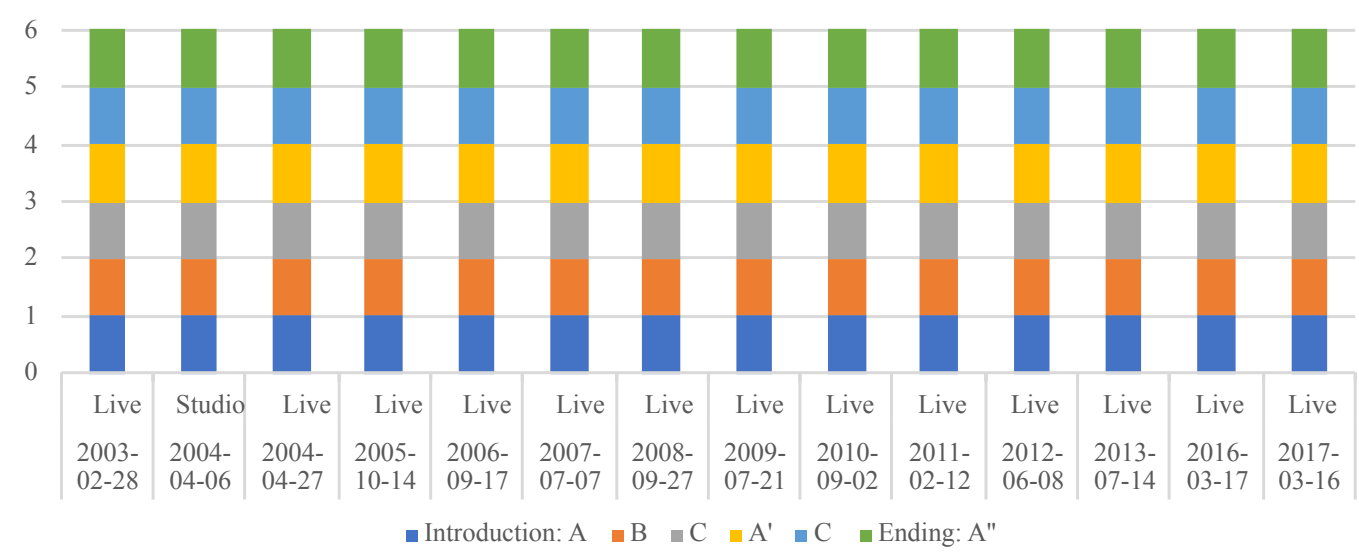

Figure 4: Annual Sample of »Salt the Skies« Forms.

\section{Epilogue}

Although three compositions by Tortoise have been discussed here in detail, the majority of Tortoise's compositions comprise the described features. Those features consist of the development of musical ideas by way of motivic accretion and depletion, thematic accretion and depletion, diminution, metric shifts, and timbral exchanges. In addition, I have pointed to how Tortoise uses the development of musical ideas to support their narrative without requiring a vocalist.

By focusing on one dimension of our corpus-study (»the spoken «) we were able to distinguish whether a piece was based on improvisation-using form as guideposts-, its form was fluid, or whether a piece was throughcomposed. From the features gathered it is clear that the post-rock genre straddles the boundaries of art music and can be seen as minimalist type of small ensemble music. With the definition of our features, I can now scan Tortoise's entire corpus, extract and catalog the different types of features, and feed these to machine learning algorithms. In the future, the study can serve as a launching point for a much larger comparative study of instrumental music by other bands of the »post-rock« genre. The gathered musical data should supplement the currently available metadata, and relationship maps between bands within the genre will be more accurate and smart enough to assume new meaning. 


\section{Bibliography}

»AAJ Staff « (2004) »Tortoise: It's All Around You.« In: All About Jazz [blog], https://www.allaboutjazz.com/its-all-around-you-tortoise-thrill-jockey-reviewby-aaj-staff.php, access: 1 June 2018.

Biber, Douglas. (1992). "The Multi-Dimensional Approach to Linguistic Analyses of Genre Variation: An Overview of Methodology and Findings. «In: Computers and the Humanities 26(5/6), pp. 331-345.

Earles, Andrew (2014). Gimme Indie Rock: 500 Essential American Underground Rock Albums 1981-1996. Minneapolis: Voyageur Press.

Holt, Fabian (2014). Genre in Popular Music. Chicago: University of Chicago Press.

Kampmann, Wolfgang (2001). »Am Anfang war der Ton.«In: Neue Zeitschrift für Musik 162(5), pp. 50-54.

Leech, Jeanette (2017). Fearless: The Making Of Post-Rock. London: Jawbone Press.

Nicholls, David (1996). »Transethnicism and the American Experimental Tradition.« In: The Musical Quarterly 80(4), pp. 569-594.

Novara, Vincent J. / Stephen Henry (2009). »A Guide to Essential American Indie Rock (1980-2005). «In: Notes 65(4), pp. 816-833.

Osborn, Brad T. (2011). »Understanding Through-Composition in Post-Rock, MathMetal, and other Post-Millennial Rock Genres. «In: Music Theory Online 17(3), http://www.mtosmt.org/issues/mto.11.17.3/mto.11.17.3.osborn.html, access: 1 June 2018.

Osborn, Brad T. (2010). Beyond Verse and Chorus: Experimental Formal Structures in Post-Millenial Rock Music. Doctor of Philosophy Dissertation, University of Washington.

Pannett, Adrian (2009). »Tortoise (Doug McCombs interview and albums guide). «In: Delusions of Adequacy, http://www.adequacy.net/2009/06/tortoise-dougmccombs-interview-and-albums-guide/, access: 19 July 2018.

Reynolds, Simon (1995). »back to the future, «In: The Wire 141, pp. 26-29.

Reynolds, Simon (1994a). »Bark Psychosis: Hex.«In: Mojo (March), http://www. rocksbackpages.com/Library/Article/bark-psychosis-ihexi, access: 12 November 2017.

Reynolds, Simon (1994b). »Shaking the rock narcotic. In: The Wire 123, pp. 28-32.

Reynolds, Simon (1996). »Tortoise: Shell On Earth.« In: Melody Maker (3 February), http://www.rocksbackpages.com/Library/Article/tortoise-shell-on-earth, access: 11 November 2017.

Reynolds, Simon (2017). »Post-Rock. «In: Audio Culture. Readings in Modern Music. Ed. by Christoph Cox and Daniel Warner. New York: Bloomsbury, pp. 509-512.

Ross, Alex (2004). »Chacona, Lamento. «In: the Rest is Noise [blog], http://www. therestisnoise.com/2004/11/chacona.html, access: 1 June 2018.

Salamon, Jeff (1996). »Tortoise: Millions Now Living Will Never Die.« In: Spin 11(12) [March], pp. 112-113.

Shields, Michael (2016). »Twenty Years Later: Tortoise's Millions Now Living Will Never Die. «In: Across the Margin [blog], http://acrossthemargin.com/twentyyears-later-tortoise/, access: 1 June 2018. 


\title{
Discography
}

Tortoise (1996). »Along the Banks of Rivers«. On: Millions Now Living Will Never Die. Thrill Jockey, THRILL 025.

Tortoise (1998). »Jetty«. On: TNT. Thrill Jockey, THRILL 050.

Tortoise (2004). »Salt the Skies«. On: It's All Around You. Thrill Jockey, Thrill 115.

\begin{abstract}
For more than 25 years the Chicago-based experimental post-rock band Tortoise has crossed over multiple popular music genres, different types of jazz music, and has made use of minimalist Western art music. In the paper, I conceptualize a twodimensional corpus study by examining multiple live recordings of three different tracks by Tortoise. I examine by what compositional techniques Tortoise generates musical ideas, and I develop a process for distinguishing whether a piece is based on improvisation-using form as guideposts-, its form is fluid, or whether it is through-composed.
\end{abstract}

